Published as: Stal, C., Tack, F., De Maeyer, P., De Wulf, A., Goossens, R. (2012). Airborne photogrammetry and LIDAR for DSM extraction and 3D change detection over an urban area - a comparative study. International Journal of Remote Sensing, vol. 34(4): 1087-1110.

\title{
AIRBORNE PHOTOGRAMMETRY AND LIDAR FOR DSM EXTRACTION AND 3D CHANGE DETECTION OVER AN URBAN AREA - A COMPARATIVE STUDY
}

\author{
Cornelis Stal $^{\star}$, Frederik Tack, Philippe De Maeyer, Alain De Wulf, and Rudi Goossens \\ Department of Geography, Ghent University, Ghent 9000, Belgium
}

(Received 25 August 2011; accepted 23 December 2011)

\begin{abstract}
*Corresponding author. Email: cornelis.stal@ugent.be
Cornelis Stal and Frederik Tack equally contributed to this article and are listed alphabetically.
\end{abstract}

A digital surface model (DSM) extracted from stereoscopic aerial images, acquired in March 2000, is compared with a DSM derived from airborne light detection and ranging (lidar) data collected in July 2009. Three densely built-up study areas in the city centre of Ghent, Belgium, are selected, each covering approximately $0.4 \mathrm{~km}^{2}$. The surface models, generated from the two different 3D acquisition methods, are compared qualitatively and quantitatively as to what extent they are suitable in modelling an urban environment, in particular for the 3D reconstruction of buildings. Then the data sets, which are acquired at two different epochs $t_{1}$ and $t_{2}$, are investigated as to what extent 3D (building) changes can be detected and modelled over the time interval. A difference model, generated by pixel-wise subtracting of both DSMs, indicates changes in elevation. Filters are proposed to differentiate 'real' building changes from false alarms provoked by model noise, outliers, vegetation, etc. A final 3D building change model maps all destructed and newly constructed buildings within the time interval $t_{2}-t_{1}$. Based on the change model, the surface and volume of the building changes can be quantified.

\section{INTRODUCTION}

City monitoring and 3D modelling of continuously and rapidly changing urban environments have become an important study field. Digital surface models (DSMs) and their derivatives are increasingly used in Earth science and the demand for DSMs has matured from a narrow research niche into an expanding market of applications (Baltsavias and Gruen 2003), going from (3D) urban planning and city management (Kolbe, Gröger, and Plümer 2005) through architectural design (Haala and Kada 2010) to microclimate studies (Rigo and Parlow 2007). At present, many different techniques exist to model the ground surface in three dimensions, such as optical (aerial and space) photogrammetry, airborne laser scanning (ALS), also called airborne light detection 
and ranging (lidar), interferometric synthetic aperture radar (InSAR), and land surveying. The first two acquisition methods are compared in this work.

3D modelling of built-up areas or man-made structures is a hard problem though, due to the structural complexity, great diversity, and high degree of detail of the urban nature. The most prominent distortions that hamper 3D reconstruction are geometrical displacement of features with a certain height above the surface, occlusion, and steep changes in slope and shadow. In the case of lidar acquisition in urban areas, the quality of the measurements suffers heterogeneously from the different types of reflecting surfaces, caused by the variety of roof materials and corresponding albedos (Böhler, Bordas, and Marbs 2003). The urban issue has been extensively researched for many decades and reported thoroughly in Berthod et al. (1995), Weidner and Förstner (1995), Gabet, Giraudon, and Renouard (1997), Förstner (1999), Jacobsen (2006), and Tack, Buyuksalih, and Goossens (in press).

Fundamentally, the DSM generation techniques by photogrammetry and by lidar are different (Asal, Smith, and Priestnall 2000). Baltsavias (1999) describes an extensive comparison between data acquisition and processing from passive optical sensors and lidar. According to Baltsavias (1999), the main differences are, respectively: passive versus active; generally frame or linear sensors with perspective geometry versus generally point sensors with polar geometry; indirect versus direct acquisition of 3D coordinates; and geometric and radiometric high-quality images versus no imaging or monochromatic images of inferior quality. For extraction of a DSM, the acquisition time and cost for lidar is generally much higher than for systematically acquired stereoscopic images; however, in general, the computation cost is lower (Gehrke et al. 2010). According to Baltsavias and Gruen (2003), lidar systems are active, are not influenced by shadows, can be employed at night, preserve surface discontinuities, allow high automation of data processing, and have relatively short production times. As such, they provide dense and accurate urban measurements. However, Baltsavias and Gruen (2003) state that they also have some disadvantages, including errors of secondary reflections close to vertical structures, a narrow flight swath, longer flight time, and more complex flight plan compared to aerial image acquisition. Identification and classification of objects based on lidar data, without any additional optical sensors or neighbourhood algorithms, is very difficult or even impossible, since the sensor only acquires a point set.

In this article, a surface model extracted from stereoscopic aerial images, acquired in 2000 , is compared with a DSM derived from airborne lidar data collected in 2009. The DSMs, derived from the aerial imagery at epoch $t_{1}$ and the lidar acquisition at epoch $t_{2}$, are further addressed in this work, respectively, as $D S M_{P H G}$ and $D S M_{\text {lidar. }}$. Three adjacent densely built-up areas in the city centre of Ghent, Belgium, are selected as a study area, each covering approximately $0.4 \mathrm{~km}^{2}$. The three areas are characterized by a high diversity in urban morphology and by some significant changed areas in terms of destructed and constructed buildings over the time interval $t_{2}-t_{1}$.

Theoretically seen, the high resolution of the aerial images and the high point density of the lidar data set should allow 3D reconstruction of the study area at the object level, i.e. building level. The surface models, generated from the two different 3D acquisition methods, are compared qualitatively and quantitatively as to what extent they are suitable in modelling the urban environment. Moreover, an effective 3D building change detection approach is introduced. The multi-temporal data sets are investigated as to what extent 3D changes can be detected and modelled over the time interval $t_{2}-t_{1}$. Height information appears to be the only true invariant to detect whether there is a 3D change (Jung 2004). In the executed research, exclusively 3D building changes are treated. The presented automatic 3D extraction approach can drastically reduce the amount of human interaction for applications such as the updating of (3D) building databases (Breunig and Zlatanova 2011) or the modelling and study of urban dynamics, e.g. expansion and densification. The objectives of this study are: 
(i) to compare the use, performance, and feasibility of aerial photogrammetry and airborne lidar in 3D surface modelling or DSM generation of a densely built-up environment, especially in the reconstruction of buildings; and

(ii) to detect and extract 3D building changes in a highly automated way by comparison of the multi-temporal data sets.

Section 2 describes the lidar and aerial image data set as well as the urban area, which is the subject of this research. Section 3 describes the DSM extraction methodology from both data sets, the post-processing and visual-qualitative analysis of the results. In Section 4, statistics are calculated for both DSMs and their comparability is discussed. Section 5 discusses an effective 3D building change detection approach. The article concludes with a brief summary and discussion of the findings.

\section{DATA SETS AND STUDY AREA}

\subsection{Lidar data set}

The used lidar data were acquired by Fugro N.V. (Leidschendam, The Netherlands) and were commissioned by the city of Ghent and the AGIV (Flemish Agency for Geographical Information), Belgium. The used Fugro Fli-Map 1000 was mounted on a helicopter and the entire campaign was executed at an average flight height of $290 \mathrm{~m}$ above ground level (agl). The relatively low flight height was necessary to get an average point density of 125 points $\mathrm{m}^{-2}$, under the condition that each object is measured with a minimal scan angle of $7.5^{\circ}$. Additional metadata is provided in Table 1.

Table 1. Properties of the used airborne laser scanner and the acquisition project.

\begin{tabular}{ll}
\hline Metadata - LiDAR campaign & \\
\hline Flight period & July 2009 \\
Measuring system & Fugro Fli-Map 1000 \\
Flight height [m] & 290 \\
Measuring frequency [Hz] & 250000 \\
Scan frequency $[\mathrm{Hz}]$ & $150-250$ \\
Range accuracy $[\mathrm{m}]=1$ sigma & 0.01 \\
Strip width [m] & 320 \\
Strip overlap [\%] & 77 \\
Point density & \\
$\quad$ Min $\left[\mathrm{P} / \mathrm{m}^{2}\right]$ & 35 \\
$\quad$ Max $\left[\mathrm{P} / \mathrm{m}^{2}\right]$ & 140 \\
Average $\left[\mathrm{P} / \mathrm{m}^{2}\right]$ & 125 \\
\hline
\end{tabular}

\subsection{Stereoscopic aerial image data set}

The stereoscopic aerial flight has been conducted over the city centre of Ghent on 22 March 2000 at noon with a Wild RC20 photogrammetric aerial frame camera, equipped with a 30/4 NATA-F lens $(f=303 \mathrm{~mm})$. The images are acquired at a flight height of approximately $1200 \mathrm{~m}$, yielding a photo scale of $1: 4000$ and a resolution of $0.09 \mathrm{~m}$ ground space distance (GSD). Each image 
covers approximately $0.7 \mathrm{~km} 2$ and has a longitudinal overlap between adjacent acquisitions of $60 \%$. The lateral side overlap between the successive flight strips is small and not usable for stereo extraction. Three stereo pairs are selected from the data set. The covered areas are selected based on a differentiated morphology and the occurrence of remarkable construction works during the acquisition of the multi-temporal data sets.

\subsection{Study area}

Three neighbouring study areas were selected in the inner city of Ghent, Belgium, all with a specific urban morphology and a total surface of $1.2 \mathrm{~km}^{2}$ (see Figure 1). It is well known that urban areas are very complex to model by both lidar and photogrammetry since steep slopes of the buildings within the area will increase the occurrence of both occlusion zones and shadow. Although this issue can be solved by acquiring data from multiple angles, it remains an important issue when the building density is high in both planimetric and altimetric directions.

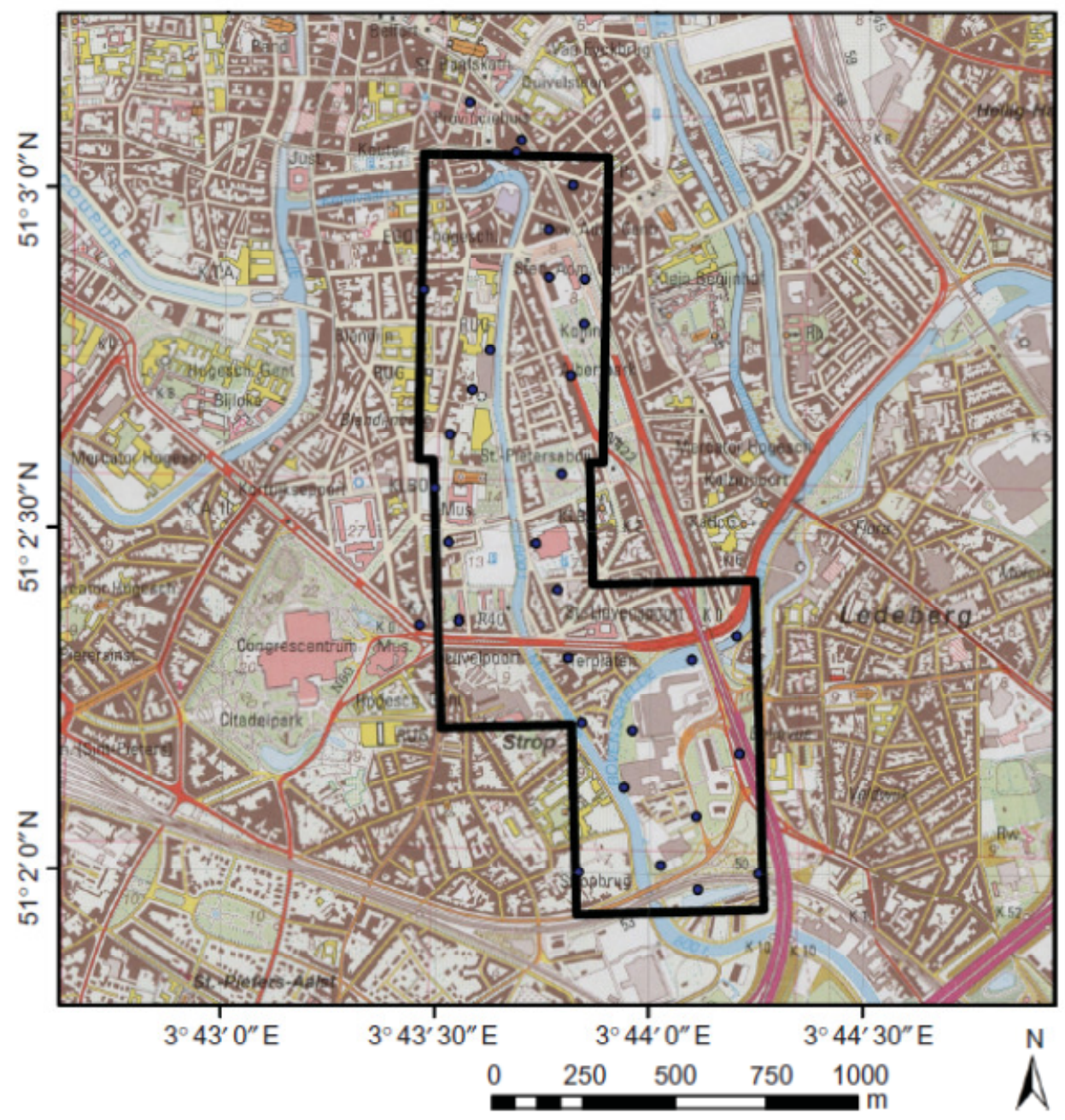

Figure 1. Overview map of the three overlapping parts of the study area. In addition, the measured GPS points used for triangulation of the aerial imagery are illustrated as blue dots (1:20,000 topographic map, NGI, 1999). 
The three selected areas are characterized by a different urban morphology and contain different building configurations. The first and most southern area is located around the 'Zuiderpoort' and consists of a widespread commercial area with some 15- to 20 -floor buildings. The second area is located around the 'Sint-Pietersplein', a big square in front of the abbey of Saint Peter. Around this old abbey, some other squares and a park are located as well. The most complex area is the 'Rectorate' area in the north, where the Ghent University administration, the university library, and some campuses are located. This dense urban area is characterized by a high diversity in building height and size and buildings are separated by narrow streets and alleys.

The urban diversity of the study area is illustrated by a topographic map (see Figure 1). The entire area is dominated by the Upperscheldt River in the south and the Muinkscheldt River from the south to the north. The east flank of the latter is characterized by three- and four-floor townhouses, two parks, and a commercial and administrative centre in the northeast.

The areas are not only selected because of their diversity of urban morphology, but also because of the fact that some important changes have taken place between the acquisition of the aerial photos in 2000 and the lidar campaign in 2009. The knowledge about these changes enables the creation of a control data set that contains newly constructed buildings. The four most prominent changes in the areas are a new office building in the south ('Zuiderpoort'), a student flat and college building in the centre ('Diamond tower'), and two new university buildings (Faculty of Economics and the Universiteitsforum or 'UFO') in the centre and the north.

\subsection{Morphological descriptor of the study areas}

To quantify the diversity of the three study areas, some metrics are calculated on the DSMs extracted from the lidar data. To describe the three data sets, a convolution filter is constructed based on a morphological filter. This concept is well known for the analysis of DSMs and digital terrain models (DTMs) in terms of edge enhancement, followed by object detection (Stal et al. 2010). A new cell value $\Delta h$ is obtained by taking a kernel $w$ around pixel $p$ in column $c$ and row $r$ $\left(c_{p}, r_{p}\right)$ and by calculating the difference between the local minimum and maximum of all height values within this kernel $\left(z_{p}, w\right)$

$$
\Delta h=\max _{\left(c_{p}, r_{p} \in w\right)}\left(z_{p}\right)-\min _{\left(c_{p}, r_{p} \in w\right)}\left(z_{p}\right)
$$

This concept is based on, respectively, the dilation and erosion component of a morphological filter (Zhang et al. 2003). The strength of the filter, in contrast with, for example, a high pass filter, is the preservation of the metric unit in the results. A given cell value defines the real height difference between the maximal height value and the minimal height value for the neighbourhood in the kernel. A high-pass filter, on the other hand, accentuates the edges of an object as well, but normalizes the values.

The results of the filter, applied on the three research areas, are summarized in Table 2. A sample of the results is illustrated in Figure 2. The DSMs have a cell size of 0.50 by $0.50 \mathrm{~m}$ and for the neighbourhood data analysis, a kernel size of $3 \times 3$ pixels is chosen.

Table 2. Statistics of the neighbourhood data analysis with a kernel size of $3 \times 3$ pixels. 


\begin{tabular}{lccccc}
\cline { 2 - 6 } & \multicolumn{5}{c}{ Focal analysis } \\
& Columns & Rows & Max $(m)$ & Mean $(m)$ & St.Dev. $(m)$ \\
\hline Rectorate & 1108 & 1769 & 63.410 & 2.312 & 4.137 \\
Sint-Pietersplein & 1030 & 1833 & 51.000 & 2.019 & 3.583 \\
Zuiderpoort & 1204 & 1933 & 48.730 & 1.814 & 3.772 \\
Total study area & 2030 & 4226 & 63.410 & 2.051 & 3.878 \\
\hline
\end{tabular}

Note: Maximum refers to maximal height difference and minimum refers to mean height difference.

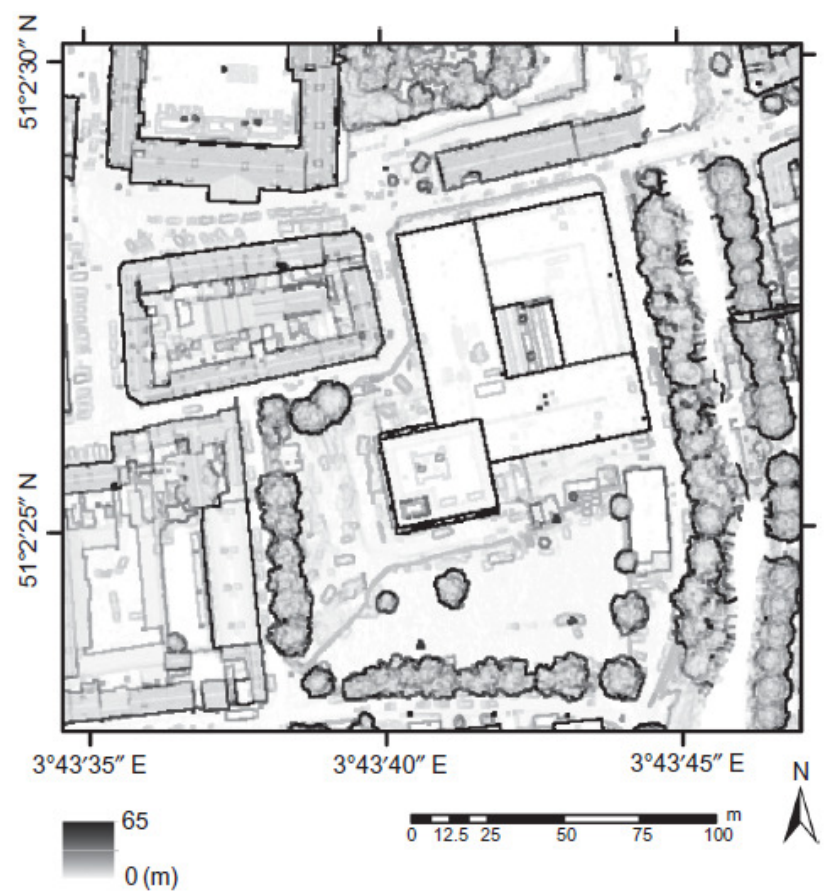

Figure 2. Sample of the morphological descriptor applied on the study area.

As demonstrated in Table 2, the highest maximal height differences are located in the 'Rectorate' area. The lowest maximal height differences are located in the 'Zuiderpoort' area. These statements are based on the values of the maximal and mean height difference per kernel. This seems to correspond with the observation that the three areas differ from each other from an urban morphological point of view. Besides, the geometrical properties are statistically different. The ratio $F_{s}$ between the standard deviations of each separated area, calculated over all local kernels $\left(c_{p}, r_{p}\right.$ $\epsilon w)$ per area, and the total study area has a maximum of 1.546, which is higher than the corresponding theoretical $F$-value $\left(F_{s}>F_{\infty, \infty}=1\right)$. The fact that the experimental $F$-value is higher than the theoretical $F$-value states the inequality of variance of the study areas. Since the above statistics are calculated for the entire data sets, the degrees of freedom are taken at infinity and the standard deviations should be exactly equal to each other. 


\section{DSM EXTRACTION METHODOLOGY}

\subsection{DSMs generated from lidar data set}

\subsubsection{Quality assessment of the lidar point set}

The quality of the lidar data has been checked by the AGIV. Important checks are executed by the creation of point density plots, as described by Kraus et al. (2006). Based on these plots, the average point density of 125 points $\mathrm{m}^{-2}$ has been calculated. The combination of perpendicular flight strips and an overlap of $77 \%$ made it possible to measure each object approximately four times and resulted in the absence of major occlusion zones on and near building façades.

The altimetric and planimetric quality assessment of the point set is determined by defining a set of reference areas. In these areas, sets of checkpoints are measured using the Real-Time Kinematic Global Navigation Satellite System (RTK GNSS). In total, 25 points are measured with a density of 1 point $\mathrm{m}^{-2}$. Predefined quality criteria were determined by the client concerning the mean error, standard deviation, root mean square error (RMSE), and skewness of the distribution of the difference between the lidar and RTK GNSS data. The criteria were set at a mean error of $0.06 \mathrm{~m}$ and an altimetric standard deviation of $0.09 \mathrm{~m}$, including the accuracy of the RTK GNSS measurements of $0.03 \mathrm{~m}$. Since the same RTK network solution calculation is used for the absolute referencing of the aerial images, an accuracy of these measurements of $0.03 \mathrm{~m}$ will be taken into account here. Experimental values of the mean altimetric error and altimetric standard deviation are, respectively, -0.02 and $0.03 \mathrm{~m}$. Low values of the skewness of the distribution of residuals are noted for every reference area, indicating no significant errors.

For this research, the quality assessment of the vendor is complemented by our own comparison of the lidar data with a set of secondary reference points (compaction points of the Flemish differential GNSS network). The resulting altimetric deviation between these reference points and the corresponding nearest lidar points equals $-0.024 \mathrm{~m}$, which is very low in comparison with the given range accuracy of $0.01 \mathrm{~m}$ and the RTK GNSS accuracy of $0.03 \mathrm{~m}$. On behalf of these measurements, a Trimble R6 GPS system was used.

\subsubsection{DSM and DTM generation}

Methods to filter ground points and non-ground points from a point set acquired by airborne lidar are numerous. Many of these methods make use of the irregular - and possibly original - vector point set, where filtering is performed using a slope-based algorithm: by morphologic operators (Vosselman 2000; Vosselman and Maas 2001), by the analysis of a triangular irregular network (TIN) (Krzystek 2003), by point segmentation and region growing (Sithole and Vosselman 2005), or by multiple-pass filtering (Bretar, Chesnier, and Pierrot-Deseilligny 2004). It is also possible to generate a bare Earth model, based on rasterized point sets. Filtering ground and non-ground points on rasterized data sets can be performed by gross error analysis (Briese, Pfeifer, and Dorninger 2002) or by analysing the difference between first and last pulse heights (Alharthy and Bethel 2002). In this research, the lidar data were processed using Terrasolid software (www.terrasolid. fi), where Axelsson's TIN-based filtering is implemented (Axelsson 1999; Coluzzi, Masini, and Lasaponara 2011). The algorithm classifies ground and non-ground points using an iterative densification of a TIN and distance criteria.

The two surface models, based on photogrammetry and lidar, are compared to each other according to a pixel-based approach. This requires an interpolation of the lidar point data set to generate, respectively, a DSM and DTM for each zone. The inverse distance weight (IDW) interpolator is applied for this purpose (Shepard 1968; Prathumchai and Samarakoon 2006). Especially when the point density is high in relation to the required resolution of the model, IDW is 
a proper method (Chaplot et al. 2006). The function for the interpolated elevation $h$ of the cell in the cth column and the th row in the model has the following form:

$$
h_{c r}=\sum_{i=0}^{n} \frac{w_{i} h_{i}}{\sum_{i=0}^{n} w_{i}}
$$

with $h_{i}$ as the elevation value of the th point of a total set of points within a given distance $\mathrm{d}$ around the centre of the cell in the cth column and the rth row, and with wi as a weight for this point. In this research, a distance threshold of $2.5 \mathrm{~m}$ is used and the weight function is defined as the inverse of the square of the distance between this point and the centre of the cell (Chaplot et al. 2006). DSM and DTM are processed at a grid size of $0.5 \mathrm{~m}$ in the UTM system, using the WGS84 ellipsoid.

The density of the original lidar point set becomes very clear after interpolation. The high point density and the angular configuration of the acquisition sensor result in a detailed representation of both the roofs and façades of buildings; in most cases, occluded areas, which are typical for conventional photogrammetry, are lacking. However, the point set only contains coordinates without information about the intensity of reflected light for the measured point.

\subsection{DSMs generated from aerial photography}

The DSM extraction process from aerial frame camera imagery is relatively well established and the core processing steps consist of the image orientation and image matching process. First, to improve the radiometry of the images, in particular texture in shadowed areas, a Wallis filter is applied (Wallis 1976). The filter performs a non-linear, locally adaptive contrast enhancement, providing good local contrast on both ends of the dynamic range of grey values.

The aerial triangulation or bundle block adjustment process determines the mathematical relationship between the camera, 2D images, and 3D object space. The interior orientation, involving the relationship between camera and $2 \mathrm{D}$ image, is determined by the measurement of the fiducial marks on each image. The exterior orientation, involving the relationship between 2D image and 3D terrain, is established based on a set of ground control points (GCPs). The 3D GCPs are measured with a Trimble R6 GPS system in RTK mode with an accuracy of $0.03 \mathrm{~m}$. Manhole covers are mainly chosen as GCPs as these are stable features over time and as their radiometry contrasts well with the surroundings. A homogeneous distribution of the GCPs over each study part is pursued (see Figure 1). However, this is not a straightforward task in a dense urban environment. Positions where a workable satellite constellation can be received and that are not located in an occluded area on both images of the stereo pair are rather rare due to the narrow streets and high-rise buildings, i.e. the so-called urban canyon problem (Cui and Ge 2003).

In Table 3, the accuracy of the image orientation process is tabulated. The residuals between an accurately measured position and a calculated position in the surface model are summarized for all GCPs in terms of an RMSE, for each of the three directions $x, y$, and $z$, planimetric circular error at $90 \%$ probability (CE90), and altimetric linear error at $90 \%$ probability (LE90).

Table 3. Geometric accuracy of the image orientation.

\begin{tabular}{lllllll}
\cline { 2 - 6 } & \multicolumn{6}{c}{ Ground control point residuals (m) } \\
& No. of GCP & RMSX & RMSY & RMSZ & CE90 & LE90 \\
\hline Rectorate & 8 & 0.031 & 0.033 & 0.106 & 0.074 & 0.186 \\
Sint-Pietersplein & 9 & 0.034 & 0.064 & 0.254 & 0.112 & 0.442
\end{tabular}


The extracted orientation parameters allow us to calculate the position of the camera $\left(X_{0}, Y_{0}, Z_{0}\right)$ and the rotation along each of the three main axes $(\omega, \phi, \kappa)$ during image acquisition for each image individually, as well as the 3D ground coordinates for each image feature.

Prior to surface model generation, the original images are resampled and rectified to an epipolar geometry based on the exterior orientation parameters of the block bundle adjustment process. Epipolar resampling or normalized image generation applies an affine transformation and aligns the images by a scaling, rotation, and translation in the $y$-direction, yielding the same geometric properties, enabling stereo vision, and enhancing matching.

The subsequent image matching process implies a description or reconstruction of the 3D environment based on 2D imagery. Image matching algorithms are able to automatically detect conjugate points or features in the images, so these corresponding points are projections of the same physical feature in object space. The surface model can be processed afterwards by calculation of the 3D position based on the measurement of the disparity or height parallax between corresponding pixels or features. The applied image correlation algorithm works according to a coarse-to-fine hierarchical matching strategy, with determination and fine-tuning of matching parameters, following a method proposed by Kanade and Okutomi (1994). The matching algorithm is in essence a combination of feature point, grid point, and 3D edge matching. The geometrically constrained cross-correlation or GC3 method (Zhang and Gruen 2006), an extension of the standard cross-correlation technique, is used to identify possible matching candidates.

In a final stage, an extended least-squares matching (LSM) method, called modified multi-photo geometrically constrained (MPG) LSM, is performed using the redundant matched features as precise approximations to check consistency, to detect mismatches, and to further refine matching results. The MPGC algorithm combines the matched feature points, grid points, and 3D edges with geometrical constraints, derived from image ray intersection conditions, epipolar constraint, and knowledge about the image orientation. The algorithm is developed by Baltsavias (1991) and based on the LSM method described in Gruen (1985).

Each extracted surface model covers an area of approximately $0.4 \mathrm{~km}^{2}$. The DSMs are processed at a grid size of $0.5 \mathrm{~m}$ in the UTM system, using the WGS84 ellipsoid. The chosen resolution provides a dense 3D description of the covered surface and leads to the best equilibrium between sufficient detail and reduction of noise or information overload. Water bodies are masked out of the model, due to their complex nature, based on a user-clicked seed point and according to the seeded region growing procedure proposed by Adams and Bischof (1994). No manual correction or editing is applied on the generated DSMs. In Figure 3, a merge of the three DSMs is illustrated. Figure 4 contains a detailed view on the DSM, draped with the produced orthoimage. 


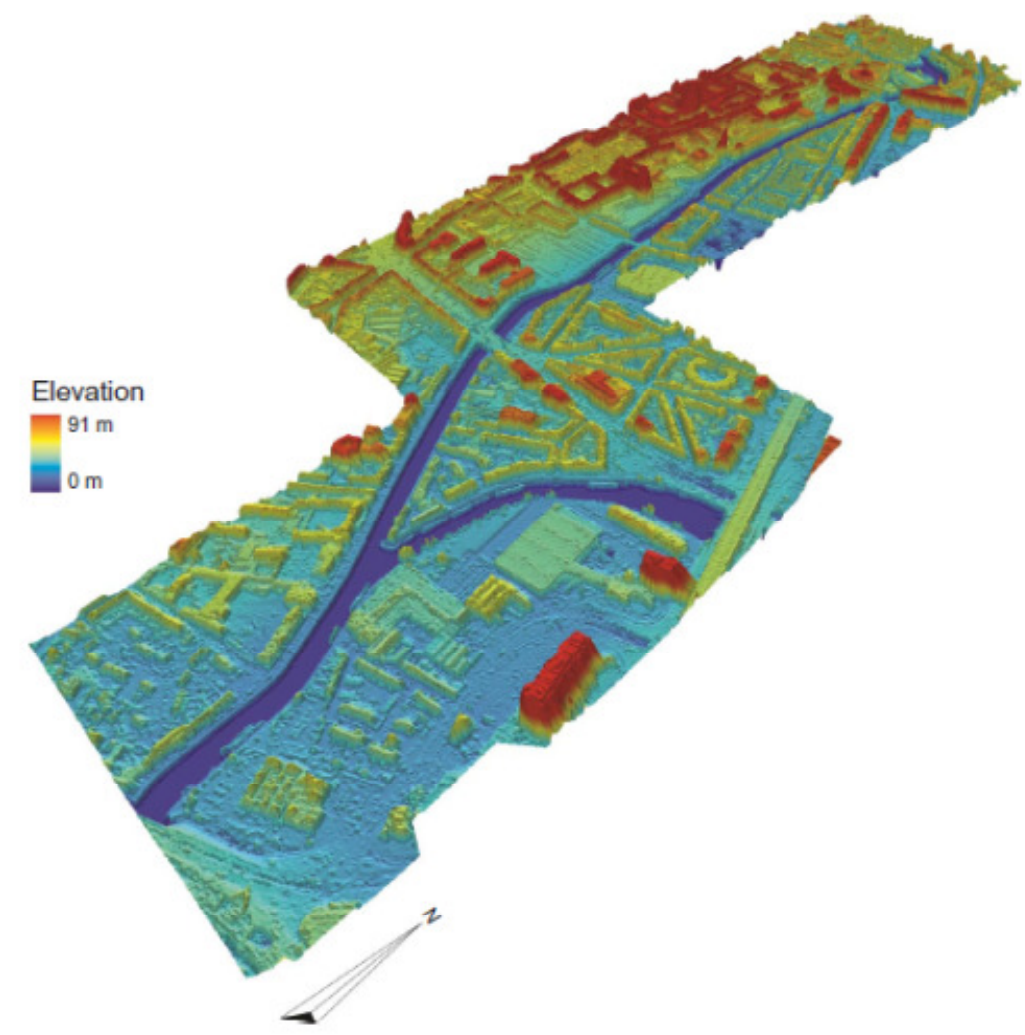

Figure 3. Perspective view on the $0.5 \mathrm{~m}$ colour-coded DSM extracted from the aerial imagery. The three adjacent test areas are merged.

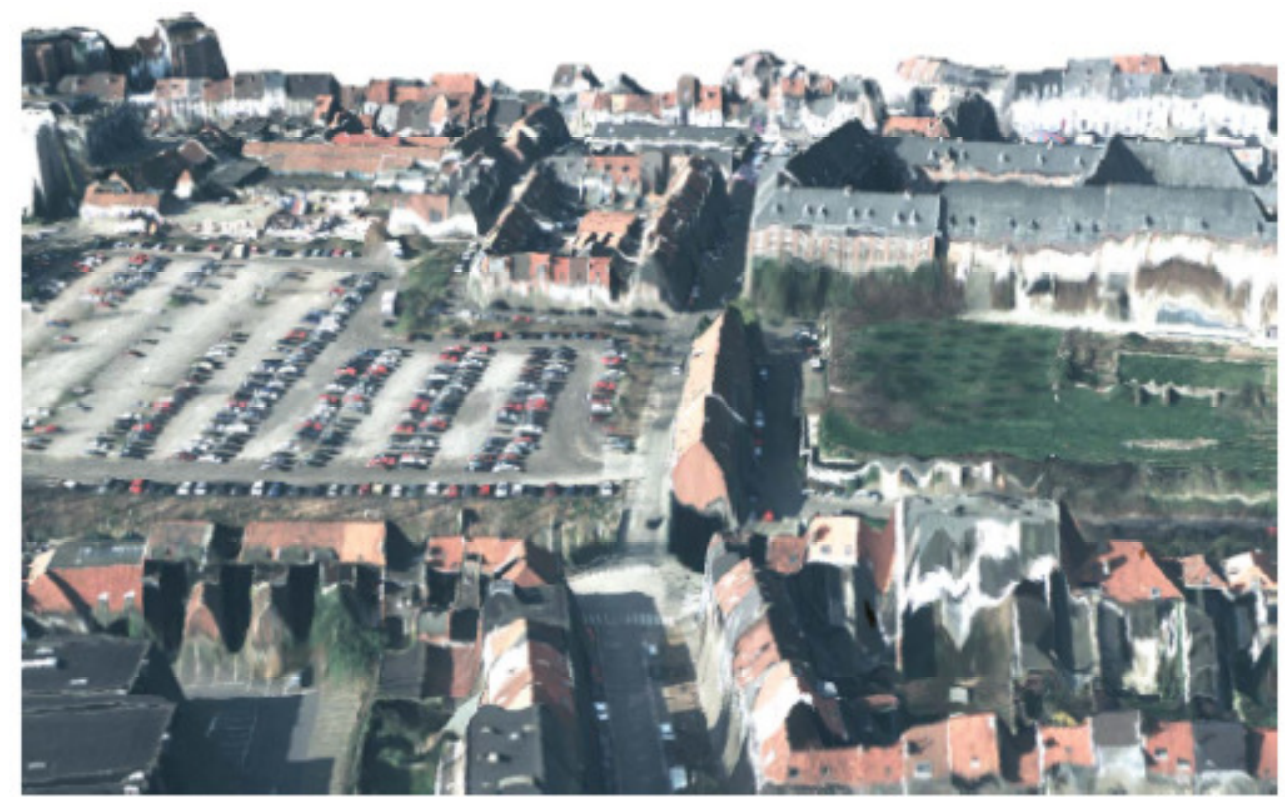

Figure 4. Extract of the surface model draped with produced orthoimage for photorealistic visualization. 
From a qualitative visual analysis, it can be observed that the terrain relief, topography, and streethouse pattern are modelled veraciously and detailed. Building walls and roof structures are modelled quite accurately with mostly sharp edges. However, the approach is not robust in the entire data set. Especially in the dense urban core, e.g. the 'Rectorate' area, vertical building walls are curved due to the large presence of occlusion and building shadow. Occluded areas appear predominantly near vertical building walls of high-rise townhouses and apartment or office blocks due to the building displacement in the imagery. The effect of occlusion increases linearly with the building height and with the distance relative to the image acquisition point. Some flaws can be detected in the vicinity of dense vegetation, e.g. city parks. Also, small urban objects such as cars, fences, lamp posts, and other city furniture yield an elevation parallax and are experienced as noise in the model, i.e. a spike or blob.

\subsection{DSM post-processing}

\subsubsection{Occlusion modelling}

Occluded or concealed areas are the main source of noise, blunders, and flaws in the models. Photogrammetric theory argues that the projection of a given terrain point must be clearly visible in at least two images in order to extract relevant elevation information. Consequently, occluded areas cannot be matched. Hence, the occlusion phenomenon in the surface models, derived photogrammetrically from aerial imagery, is modelled. Occlusion is also present in but is less pronounced or even negligible due to the many overlapping flight strips in different directions.

To quantify the occlusion, a standard ray tracing algorithm is applied on the three extracted models. The position of the camera $\left(X_{0}, Y_{0}, Z_{0}\right)$ and the rotation along each of the three main axes $(\omega, \phi, k)$ during image acquisition for each image individually is already calculated by the image orientation process. In zone 'Rectorate', $15.79 \%$ of the ground surface is occluded by buildings and other man-made features. Occlusion is, respectively, $12.54 \%$ and $11.31 \%$ for zone 'SintPietersplein' and 'Zuiderpoort'. Occluded areas can be filtered from the models based on the generated occlusion mask.

\subsubsection{DSM noise reduction}

An edge-preserving smoothing filter is used to remove noise and unwanted local relief from the generated surface models, while preserving building discontinuities (Jacobsen 2006). More specific, a small $5 \times 5$ median box filter is applied on the models. The filter changes the value of each pixel by looking at the surrounding pixels within the $5 \times 5$ moving window and by arranging all values in sequential order. Next, the 50th percentile value is assigned to the centre pixel. As the median value is assigned, the influence of unrepresentative pixels or outliers within the kernel will not affect the new pixel value significantly.

\section{DSM COMPARABILITY ANALYSIS}

\subsection{Overall comparability of the DSMs}

Before analysing the DSMs for each study area separately, the comparability between the photogrammetric model DSM $\mathrm{PHG}_{\text {and }}$ ane lidar model $\mathrm{DSM}_{\text {lidar }}$ will be examined for the entire study area. The models are compared relatively to each other by pixel-wise differencing of the DSM values. The difference digital surface model $\left(D S M_{D}\right)$ is the result of subtraction of the photogrammetric model from the lidar model and the pixel values represent differences in height between DSM lidar $_{\text {and }}$ DSM PHG. $_{\text {. }}$

First, the differences between both models are investigated for zones that are deemed not to have changed over the time interval $t_{2}-t_{1}$. Under ideal circumstances, the difference in height between the DSM generated by the photogrammetric process and by the lidar data processing should be 
zero for the non-changed areas. However, this is not the case for several reasons, such as modelling errors, occlusion, local relief induced by cars and other moving objects, changes in phenological state of vegetation, smoothing as a consequence of DSM interpolation, etc. Two point sets of each 100 samples are selected on the street level and roof level, respectively. The point samples are randomly distributed over exclusively unchanged zones. Statistical parameters for the height differences, extracted from DSMD based on the point samples, are given in Table 4.

Table 4. Statistical measures for height differences extracted from DSMlidar minus DSMPHG based on a set of 100 points on street and roof levels, respectively. The point samples are randomly distributed over exclusively unchanged parts of the study area.

\begin{tabular}{lcccccc} 
& \multicolumn{6}{c}{ Descriptive statistics for a random set of points (m) } \\
& Min & Max & Mean & St. Dev. & MAE & RMSE \\
\hline Street level & -0.221 & 0.974 & 0.195 & 0.252 & 0.199 & 0.318 \\
Roof level & -0.924 & 0.809 & 0.146 & 0.320 & 0.293 & 0.351 \\
\hline
\end{tabular}

Based on the calculated statistics, it appears that the elevation differences between both models do not significantly differ from zero in unchanged areas. The results indicate the comparability of the two produced DSMs.

Then, descriptive statistics are calculated for the entire study area or for all pixels of DSMD . Results are summarized in Table 5. Different thresholds, defined by a given maximal tolerated difference between the $\mathrm{DSM}_{\mathrm{PHG}}$ and $\mathrm{DSM}_{\text {lidar }}$, are applied to cut off the height differences. To interpret the statistical values, it is assumed that both DSMs are parallel and that also the height values in DSMD are perpendicular to the reference plane.

Table 5. Statistical measures for DSM $M_{L I D A R}$ minus $D S M_{P H G}$.

\begin{tabular}{lcccccc}
\hline \multicolumn{7}{c}{ Descriptive statistics for DSM $_{\boldsymbol{D}}(\mathbf{m})$} \\
\multicolumn{1}{c}{ Threshold } & Min & Max & Mean & St. Dev. & MAE & RMSE \\
\hline no threshold & -43.2 & 58.3 & 1.199 & 5.777 & 2.722 & 5.901 \\
$\mathbf{2 5}$ & -25.0 & 25.0 & 0.906 & 4.608 & 2.409 & 4.696 \\
$\mathbf{1 0}$ & -10.0 & 10.0 & 0.242 & 2.631 & 1.504 & 2.642 \\
$\mathbf{5}$ & -5.0 & 5.0 & 0.117 & 1.438 & 0.911 & 1.442 \\
$\mathbf{2 . 5}$ & -2.5 & 2.5 & 0.121 & 0.823 & 0.580 & 0.832 \\
$\mathbf{2}$ & -2.0 & 2.0 & 0.119 & 0.689 & 0.502 & 0.699 \\
$\mathbf{1 . 5}$ & -1.5 & 1.5 & 0.111 & 0.547 & 0.416 & 0.558 \\
$\mathbf{1}$ & -1.0 & 1.0 & 0.098 & 0.396 & 0.319 & 0.408 \\
$\mathbf{0 . 5}$ & -0.5 & 0.5 & 0.076 & 0.233 & 0.204 & 0.245 \\
\hline
\end{tabular}

The calculated standard deviation, mean absolute error (MAE), and RMSE behave more or less linearly with respect to the threshold value. This is to be expected since higher thresholds enclose more noise and outliers. The statistics, especially at higher thresholds, show evidence of changes that have occurred during the time interval $t_{2}-t_{1}$, e.g. destructed and constructed objects. 
Based on Table 5, the mean and standard deviation are plotted against a given threshold value and illustrated in Figure 5. For threshold values lower than approximately $7.5 \mathrm{~m}$, the mean error is not linear but stabilizes around a value of $0.11 \mathrm{~m}$. As the height differences larger than $7.5 \mathrm{~m}$ can be considered as mainly multi-temporal changes between both models, a value of $0.11 \mathrm{~m}$ can be accepted as the systematic offset between the two models. In this particular case, DSM lidar $_{\text {in }}$ altimetric heights are bigger than DSM $\mathrm{PHG}_{\text {heights. }}$

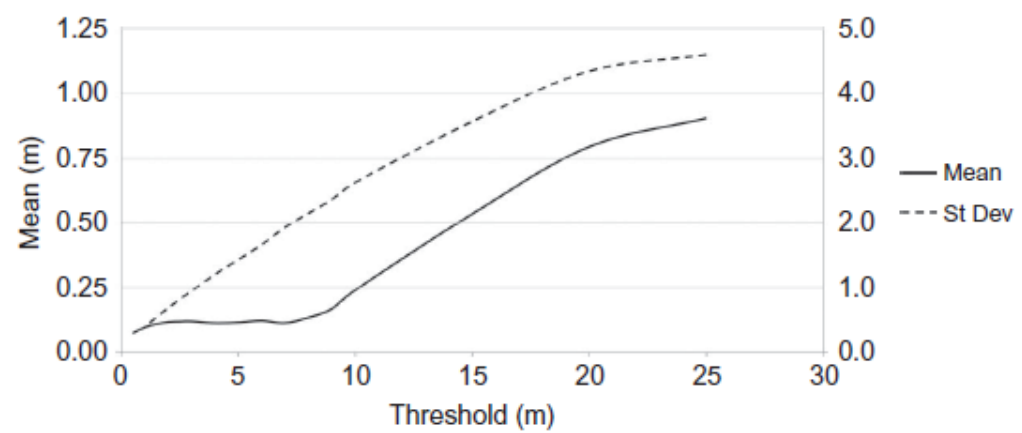

Figure 5. Plot of the mean and standard deviation (SD) against different threshold values for the height differences in DSMD .

\subsection{Comparability of the data for the different study areas}

The differences between the data sets are evaluated for the three study areas by comparing each set with a random sample of 3D reference points. The 36 reference points are measured using RTK GNSS on the bare Earth at positions where no changes are assumed over the time interval $t_{2}$ - $t_{1}$. The accuracy of this control set is $0.03 \mathrm{~m}$, which is theoretically much higher than the accuracy of both photogrammetric and LiDAR data sets. The comparison itself is performed using a one-way analysis of variance (ANOVA) (Kutner et al. 2005), where the ideal situation is formulated by the following null hypothesis $\left(\mathrm{H}_{0}\right)$, where all population mean elevation values $\mu$ of the different data sets are equal. The alternative hypothesis states that at least one population mean elevation is different from another study area:

$$
H_{0}: \mu_{G P S}=\mu_{P H G}=\mu_{L i D A R} \text { and } H_{A}: \text { at least one } \mu \text { value is different from the rest. }
$$

Before performing the ANOVA, a test of homogeneity of variance is performed by calculating the Levene's statistic (Kutner et al. 2005). The corresponding Levene's statistic gives $(0.05<p<0.41)$, which states the assumption of homogeneity of variance and allows further execution of the ANOVA.

The reference height points are compared with the corresponding height values from the $D S M_{\text {lidar }}$ and DSM $M_{P H G}$ model per study area using ANOVA. The results of the ANOVA are given in Table 6. Based on the results in the table, the null hypothesis can be accepted with a $95 \%$ level of significance for each study area. The calculated F-values are smaller than the critical F-values, with a $95 \%$ confidence interval. This means that no significant difference can be detected between the DSM generated by photogrammetry, the LiDAR DSM, and the GNSS control set $(0.05<p<$ 0.95). In other words, DSM $M_{L I D A R}$ and DSM ${ }_{P H G}$ are statistically equal for all study areas. 
Table 6. Results of the ANOVA, where the three different data sets or groups are compared with each other ( $S S$ is the sum of squares; $d f$ is the number of degrees of freedom; $M S$ is the mean square, $F$ is the $F$-value; $p$ is the probability value; and $F$-crit is the critical $F$-value).

\begin{tabular}{llllllll} 
& & \multicolumn{7}{c}{ ANOVA } & & & \\
\cline { 2 - 7 } & Source of Variation & $S S$ & $d f$ & $M S$ & $F$ & $p$ & F crit \\
\hline \multirow{4}{*}{ Rectorate } & Between groups & 11.588 & 2 & 5.794 & 0.080 & 0.923 & \multirow{2}{*}{4.403} \\
& Within groups & 1729.867 & 24 & 72.078 & & & \\
& Total & 1741.455 & 26 & & & & \\
\hline \multirow{4}{*}{ Sint- } & Between groups & 9.441 & 2 & 4.721 & 0.071 & 0.931 & \multirow{2}{*}{3.316} \\
Pietersplein & Within groups & 1985.679 & 30 & 66.189 & & \\
& Total & 1995.120 & 32 & & & & \\
\hline \multirow{5}{*}{ Zuiderpoort } & Between groups & 1.380 & 2 & 0.690 & 0.636 & 0.537 & \multirow{2}{*}{3.316} \\
& Within groups & 32.576 & 30 & 1.086 & & & \\
& Total & 33.957 & 32 & & & & \\
\hline
\end{tabular}

\section{3D BUILDING CHANGE DETECTION}

The multi-temporal data sets are investigated as to what extent 3D changes can be detected and modelled over the time interval $t_{2}-t_{1}$. The emphasis is exclusively on 3D building changes. A human operator can easily detect and visually interpret the changes from an initial difference change map. However, this is a time-consuming and a not cost-effective task, especially if a big area needs to be analysed. Highly automated 3D building change detection and differentiation from noise, errors, and other off-terrain objects such as trees can be considered as a complex problem. An effective, automated 3D building change detection approach is introduced below. The fundamental steps of the approach are illustrated with a sample of the entire data set, i.e. the area where the new college campus 'Diamond tower' is established.

\subsection{Thresholding difference map}

The two surface models acquired at different instances of time $t_{1}$ and $t_{2}$ are compared to each other to detect and quantify 3D building changes. The applied change detector is based on a pixelwise differencing of the DSM values (Lu et al. 2004; Radke et al. 2005):

$$
D S M_{D}(c, r)=D S M_{L i D A R}(c, r)-D S M_{P H G}(c, r)
$$

where $D S M_{D}$ is the difference surface model, $D S M_{\text {lidar }}$ is the lidar surface model acquired at $t_{2}$, $\mathrm{DSM}_{\mathrm{PHG}}$ is the photogrammetrically derived surface model acquired at $t_{1}$, and $(c, r)$ is the pixel or height value at column $c$ and row $r$.

The difference surface model not only highlights terrain-dependent 'real' changes over time $t_{2}-t_{1}$, but also noise and modelling errors, as illustrated in Figure 6. For example, 3D points collected on cars and city furniture such as fences, lamp posts, and flower boxes induce local relief, spikes and pits, and are modelled differently in both DSMs depending on the characteristics and resolution of the particular acquisition method. Moreover, non-fixed objects such as cars are not located on the same place anymore over the time interval $t_{2}-t_{1}$. 


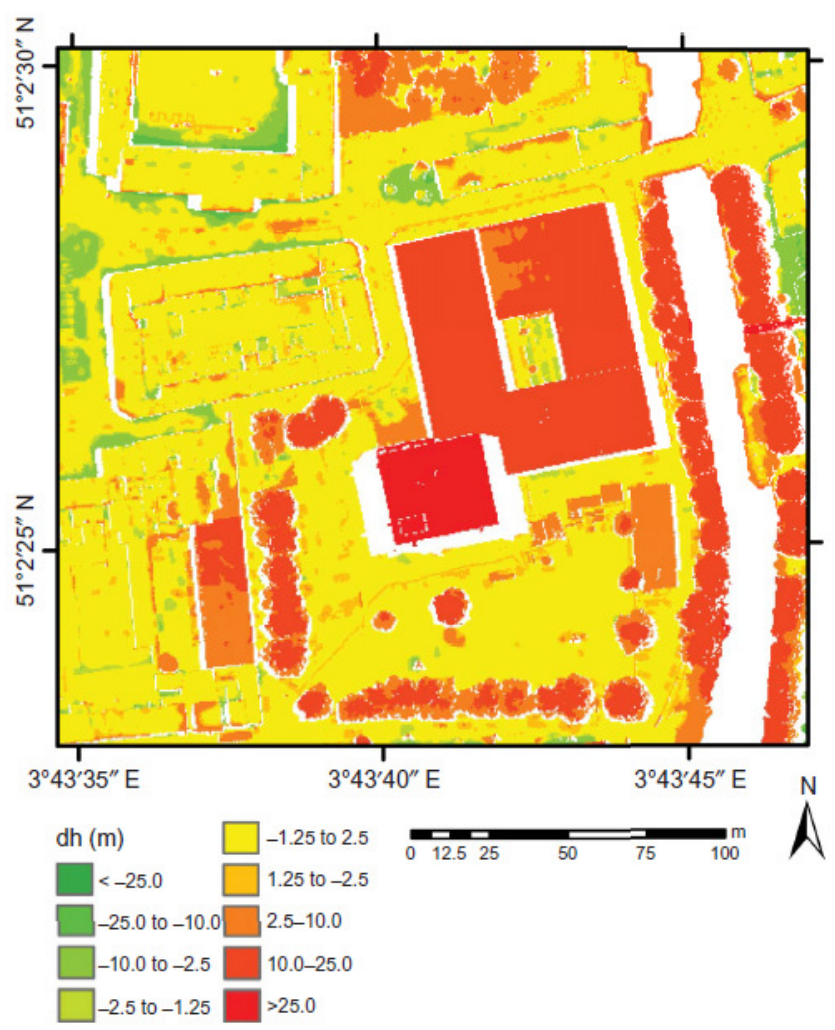

Figure 6. Sample of the difference DSMD between the LiDAR and photogrammetric surface models.

To differentiate unchanged parts, noise, errors, and 3D modelling deficiencies from real significant changes, DSMD needs to be thresholded. Determination of a suitable threshold to identify a significant real building change is based on the mean difference between $D_{S} M_{\text {lidar }}$ and $D S M_{P H G}$ for both times and on contextual information, i.e. the legal minimum building floor height in the city of Ghent (Stad Gent 2004). Both values correspond with a threshold value $T$ of $2.5 \mathrm{~m}$.

$$
D S M_{D}= \begin{cases}D S M_{D+}(c, r) & \text { if } D_{S M_{L i D A R}(c, r)-D S M_{P H G}(c, r) \geq T} \\ D S M_{D 0}(c, r) & \text { if }\left|D S M_{L i D A R}(c, r)-D S M_{P H G}(c, r)\right|<T \\ D S M_{D-}(c, r) & \text { if } \operatorname{DSM}_{L i D A R}(c, r)-D_{P H G}(c, r) \leq-T\end{cases}
$$

The thresholded difference surface model $D S M_{D}$ indicates signed changes in elevation, with positive values $\left(\mathrm{DSM}_{\mathrm{D}_{+}}\right)$indicating building construction and negative values $\left(\mathrm{DSM}_{\mathrm{D}_{-}}\right)$pointing at building destruction over time $t_{2}-t_{1}$. The detected changes for the used threshold value of $2.5 \mathrm{~m}$ and the influence of this threshold value are illustrated in Figure 7 for the sample data set. In addition to the used threshold of $2.5 \mathrm{~m}$, binary maps are also illustrated for less ideal thresholds. In the case of a low threshold of $1.0 \mathrm{~m}$, too much noise is present in the change map. In the case of a high threshold of $5.0 \mathrm{~m}$ (parts of), changed buildings are not detected in the change map. 

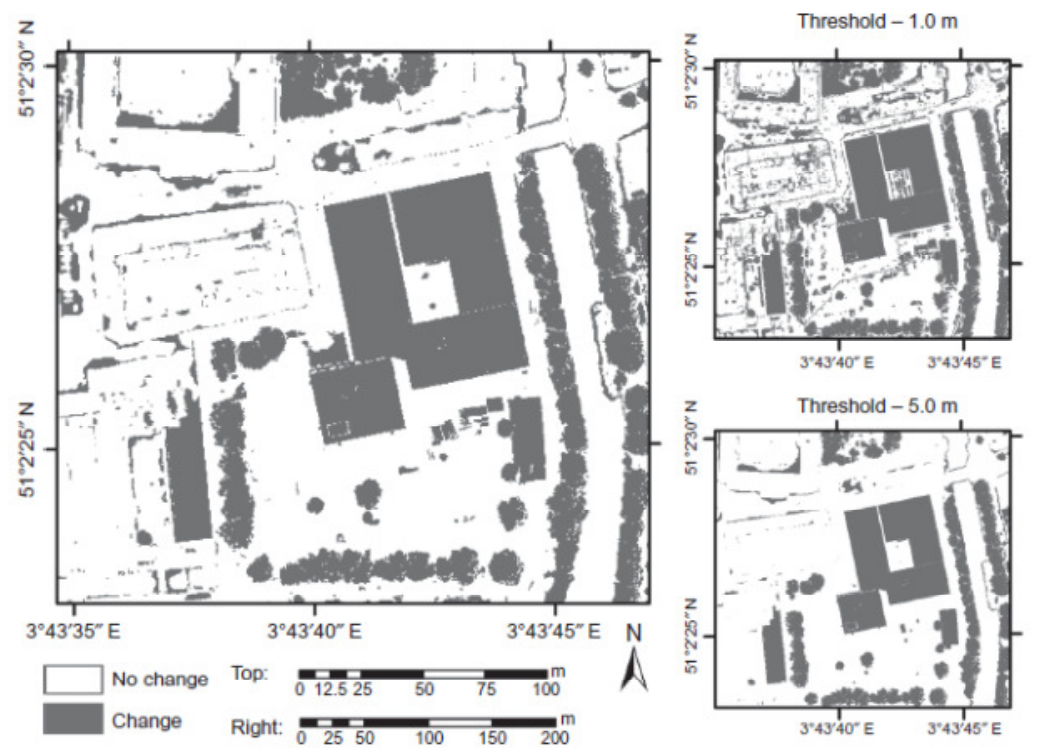

Figure 7. Thresholded binary change map. The effect of implementation of different thresholds is illustrated.

\subsection{Building identification and differentiation}

However, most model deficiencies and errors are removed, in addition to terrain-dependent changes over the time interval $t_{2}-t_{1}$, thresholded still contains outliers and anomalies due to noise, model errors, model-specific characteristics, etc. Errors due to presence of vegetation and linearshaped errors due to the bell-shaped reconstruction of buildings, caused by occlusions, are the most common types of 'false' changes. Below, filters are proposed to differentiate these false alarms from real building changes.

\subsubsection{Blunder filter}

Polyline-shaped false alarms and small islands still remain after thresholding the difference surface model DSM $M_{D}$. The linear-shaped errors mainly occur in the dense urban core, parallel to the street network and the rows of connected houses. These errors are remains of the bell-shaped reconstruction of buildings in the model, caused by geometrical displacement, residual occlusion, height discontinuities, and shadow. To remove most of the linear artefacts and small clusters of pixels, a morphological filtering method can be applied as proposed by Chaabouni-Chouayakh et al. (2010). All filters in mathematical morphology are based on erosion and dilation, which are performed over a neighbourhood specified by a moving window or structural element (Soille 2003). Erosion and dilation are defined as follows:

$$
\left[E_{S}\left(D S M_{D}\right)\right]\left(c_{p}, r_{p}\right)=\min \{w\}
$$

and

$$
\left[D_{S}\left(D S M_{D}\right)\right]\left(c_{p}, r_{p}\right)=\max \{w\}
$$


where $E_{S}$ is the erosion operator with the structural element $S, D_{S}$ is the dilation operator with structural element $S, D_{S}$ is the difference surface model, $\left(c_{p}, r_{p}\right)$ is the centre pixel of the moving window, and $\mathrm{w}$ is the neighbourhood of $\left(c_{p}, r_{p}\right)$, defined by the structural element.

A morphological opening operation is applied on $D S M_{D}$, which is defined by the function $D_{S}\left(E_{S}\left(\mathrm{DSM}_{\mathrm{D}}\right)\right)$ and executes an erosion followed by dilation. The kernel is parameterized at $10 \times 10$ pixels, corresponding to $25 \mathrm{~m}^{2}$ or the minimum area of a living room and kitchen for a household (Stad Gent 2004). After morphological filtering, most linear artefacts and insignificant clusters are removed from the change map (see Figure 8).

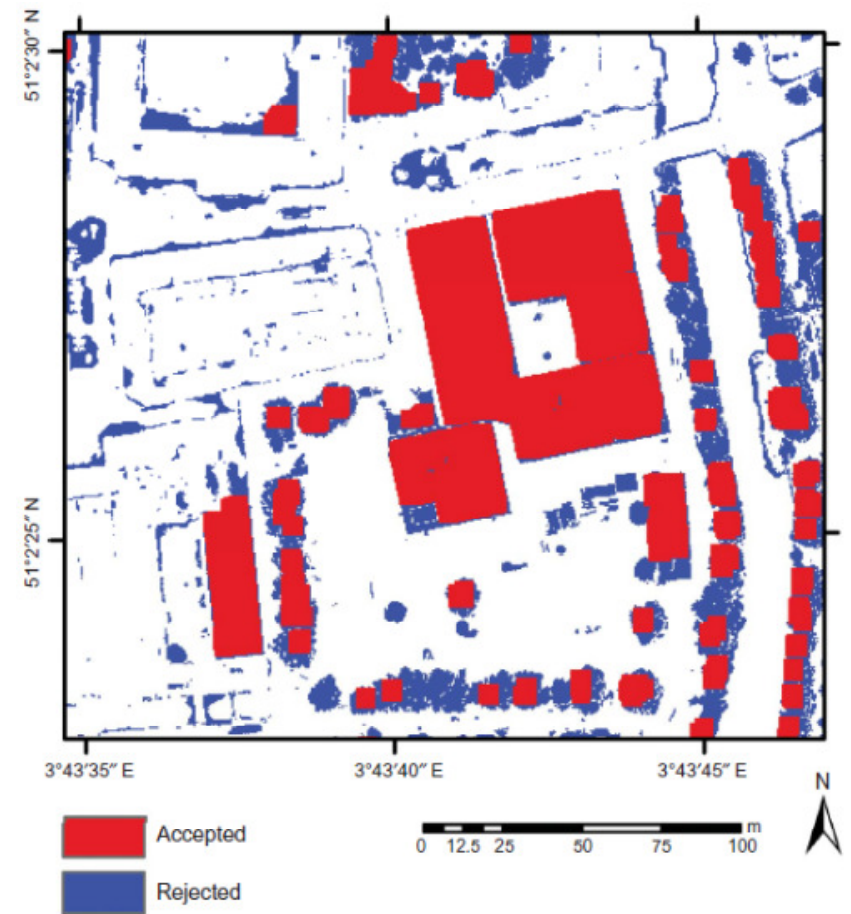

Figure 8. Blunder filter, removing linear artefacts, and insignificant clusters from the change map.

\subsubsection{Vegetation filter}

The vegetation within the study area consists mainly of individual deciduous trees, gardens, and two small parks. Due to the alteration in the phenological state of the present vegetation over time $t_{2}-t_{1}$ and seasonal effects, vegetation is modelled differently in DSMPHG and $D S M_{\text {lidar }}$ and results in the detection of $3 \mathrm{D}$ changes. The photogrammetrically derived surface model $\mathrm{DSM}_{\mathrm{PHG}}$ is a winter acquisition, while DSM $\mathrm{LIDAR}_{\text {is }}$ acquired in the summer season. Mainly the large, freestanding deciduous trees are problematic, as they are not modelled in $\mathrm{DSM}_{\mathrm{PHG}}$ due to reflectance of the ground surface. However, many 3D points are collected on the trees in $\mathrm{DSM}_{\text {lidar. }}$.

To differentiate only the 3D building changes, vegetation needs to be classified and filtered out of the difference surface model DSMD. Due to the lack of multispectral image data or colour infrared $(\mathrm{CIR})$ imagery, common vegetation classification based on the normalized difference vegetation index (NDVI) is not feasible (Rottensteiner et al. 2007). Also an object-based image analysis (OBIA) does not provide satisfying results (Blaschke 2010). Due to the winter acquisitions of the imagery, most of the individual trees are not identified as vegetation in OBIA since the image pixels mainly contain the radiometry of the ground surface, visible through the tree branches. 
In this research, a variant of a contrast filter is applied to differentiate artificial objects (e.g. buildings) from natural objects (e.g. trees) (Elberink and Maas 2000). The differences between local height contrast within artificial and natural objects are used to distinguish both, assuming that roofs of buildings mostly consist of planar or at least smooth surfaces. This 'roughness' metric will give irregular patterns for vegetation while measuring sharp shapes for buildings.

The morphological or blunder filter, presented in the last paragraph, will result in regions of neighbouring cells, corresponding to changes. Regions will be grouped to clusters of cells, with no connection values between each separated cluster. For each cluster, the 'roughness' is calculated by the mean of all focal height contrasts within the cluster. The outcome of this operation is illustrated in Figure 9 for the sample data set, where red-coloured clusters correspond with artificial objects, i.e. buildings, and blue clusters correspond with natural objects, i.e. vegetation. The blue clusters, characterized by high roughness, are removed from the change map.

\subsection{Polygon vector change map}

Filtered $D S M_{D}$, indicating whether the elevation value of a pixel is changed over the time interval $t_{2}$ - $t_{1}$, can be subsequently converted into a polygon vector layer by applying polygon fitting on the different clusters of extracted pixels. Next, the polygons can be simplified according to a method based on Douglas and Peucker (1973). The line simplification method removes small fluctuations, extraneous bends, and redundant vertices from its boundary while preserving the essential shape. The resulting vector map consists of polygons indicating a building construction or destruction.

\subsection{Final 3D building change model}

The polygon vector change map can be applied to extract the height for the detected build- ing changes. Elevation is extracted from $D M_{D_{+}}$in the case of construction and from $D_{S M_{D-}}$ in the case of destruction. The resulting 3D building change model is illustrated in Figure 10. For reasons of visualization, interpretation, and analysis, the changed buildings are merged with the DSM layer, which is draped with the orthoimage generated from the aerial image data set. Newly constructed buildings are reproduced in red colour, while demolished buildings are represented in blue. 


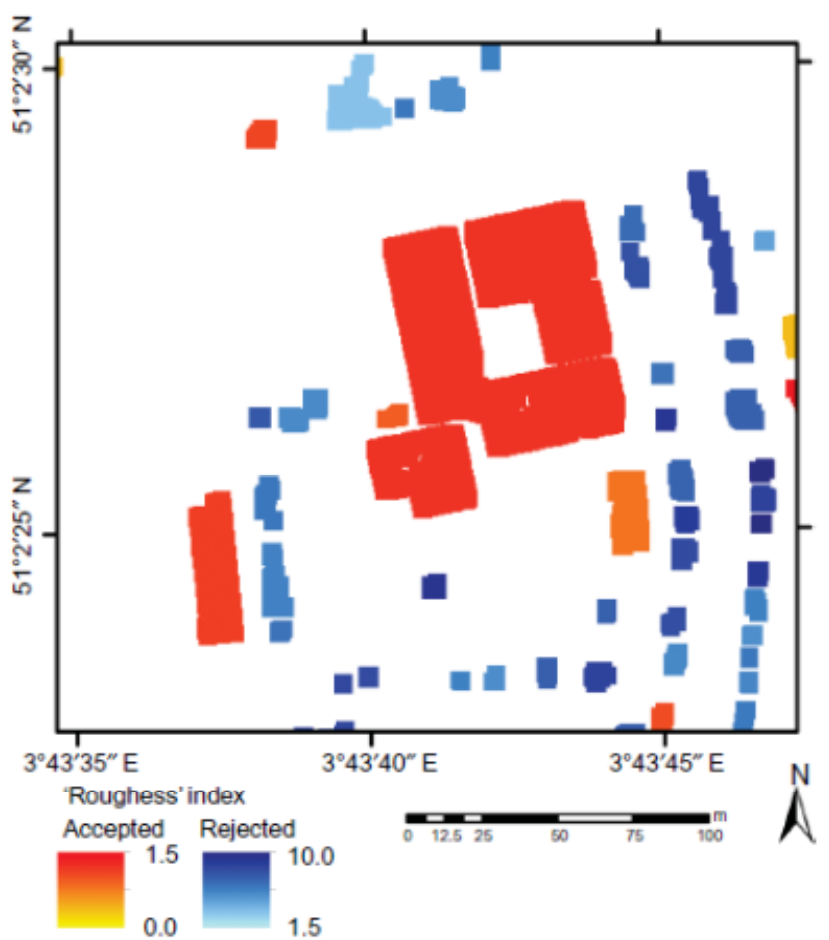

Figure 9. Differentiation of artificial objects from natural objects based on a roughness metric.

Quantification of the surface and volume of destructed and constructed buildings within the global study area is straightforward, based on the planimetric and altimetric dimensions of the detected $3 D$ changes. According to the presented 3D change detection approach, approximately $21,725 \mathrm{~m}^{2}$ or a volume of $281,504 \mathrm{~m}^{3}$ is constructed over time interval $t_{2}-t_{1}$, yet approximately $19,425 \mathrm{~m}^{2}$ or $141,212 \mathrm{~m}^{3}$ is destructed.

The resulting 3D building change model, illustrated in Figure 10, is assessed by visual analysis and a field comparison. The four most prominent changes within the study area are detected properly, i.e. a new office building in the south ('Zuiderpoort'), a student flat and college building in the centre ('Diamond tower'), and two new university buildings (Faculty of Economics and the Universiteitsforum or 'UFO'), respectively, in the centre and the north. Also smaller changes, such as individual single-family dwellings are detected properly in nearly all cases.

It must be mentioned that buildings need to be changed significantly (in height) to enable their detection. If a building is destructed and a new one is constructed on the same surface without any change in volume, the building will not be detected by the presented approach. In some cases, an old building has been replaced by a construction covering a bigger surface, but not necessarily a bigger height. In such a case, only the parts of the new building that are raised on the non-built surface will be detected, resulting in sometimes odd-shaped polygons. This is, for example, the case for the 'UFO' building.

Destructed buildings, such as a large hangar in the south and some dwellings in the neighbourhood of the Faculty of Economics, are detected and modelled correctly as well. However, there is a slight overestimation of destructed objects, due to remaining occlusion zones and some trees that could not be filtered out. Such false alarms occur, for example, in the patio of Saint Peter's abbey. In this case, the erroneously detected changes fall within the criteria of a height difference of $2.5 \mathrm{~m}$ and area difference of $25 \mathrm{~m}^{2}$. 


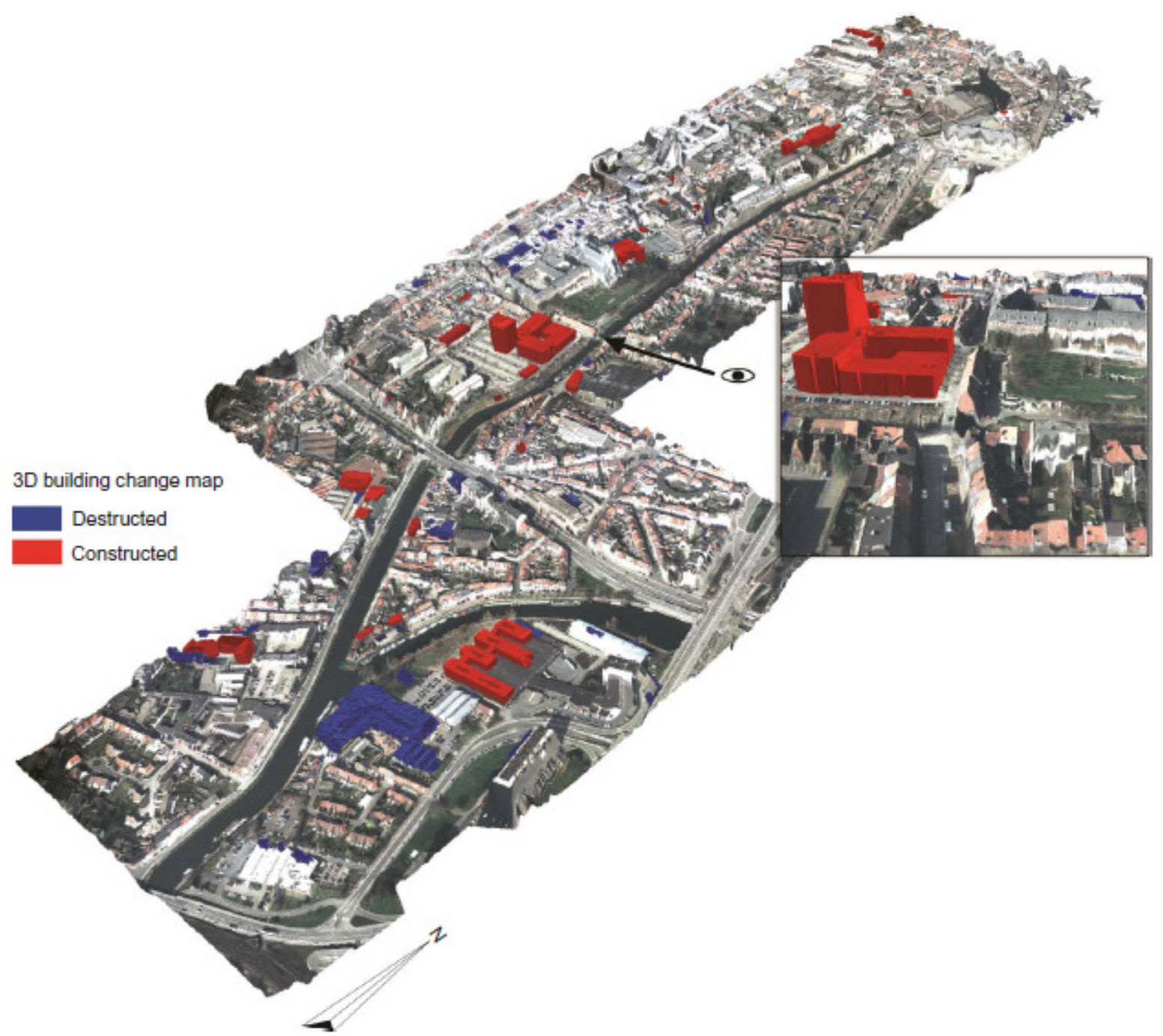

Figure 10. Final 3D building change model for the global study area in perspective view with a zoom on the 'Diamond tower' area. The detected building changes are draped on the DSM and orthoimage, generated from the aerial imagery.

To illustrate the robustness of the 3D change detection approach, it is interesting to mention that a funfair took place on Saint Peter's square at the moment of the acquisition of the aerial images, while the square was empty during the lidar acquisition. As demonstrated in the final 3D change model, many of the fairground attractions are detected as destructed objects.

\section{CONCLUSION AND DISCUSSION}

In the presented research, DSMs are generated from both stereo aerial imagery and ASL data. This is done for three adjacent areas, characterized by varying urban morphology. Notwithstanding the fundamental differences between the study areas, the resulting surface models of both approaches are highly comparable in a qualitative and quantitative/statistical way for all zones (see Section 4, concerning the DSM comparability analysis). Baltsavias (1999) and Asal, Smith, and Priestnall (2000) already stated that, although lidar and photogrammetry are different 
measurement systems, results can be strikingly comparable. The techniques have the potential to be highly complementary in terms of degree of detail, coverage size, necessity for spectral information, etc.

The results from both approaches are clearly suitable in terms of quality and accuracy to model an urban environment and for veracious 3D reconstruction of individual buildings or building blocks and other urban features. However, the indirect derivation of elevation data, based on image matching and parallax measurements, usually exhibits more noise and larger blunders than observed in raw lidar data. The projection of the three-dimensional urban environment on a 2D image plane invariably causes distortions and information loss, e.g. occlusion, shadow, image displacement, and edge smoothing due to interpolation near discontinuities. This hampers the 3D photogrammetric reconstruction.

Visual analysis of the results from the 3D change detection approach points out that even with the generation of an occlusion mask, a substantial amount of occluded areas is still present in $\mathrm{DSM}_{\mathrm{PHG}}$. Occlusion is most present in zone 'Rectorate' due to the high building density, high-rise townhouses, and narrow streets. The effects of occlusion and other distortions, present in DSM $\mathrm{PHG}_{\text {, }}$ could be reduced in future research by photogrammetric processing of multiple overlapping images instead of processing stereo pairs. A multiscopic approach can drastically reduce the amount of occlusion and subsequent flaws in DSM modelling (Tack, Buyuksalih, and Goossens, in press).

In addition to the comparison of both acquisition techniques, an effective 3D building change detection approach is introduced. The emphasis focuses primarily on 3D building changes. The investigated and described methodology for extracting 3D building changes is highly automated and is able to yield a 3D building change model for any input of two multi-temporal DSMs. The different parameters can be set by an operator, depending on the quality of the DSMs, the type of study area, and the applicable construction permit regulations. The 3D change detection workflow is schematized in Figure 11. The semi-automatic approach can drastically reduce the amount of human intervention for applications such as the updating of building databases or the monitoring and modelling of urban growth.

DSM errors, model noise, lack of quality, and insufficient detail or low spatial resolution have a significant impact on the accuracy and performance of the change detection approach. Filtering of the initial difference surface model DSMD is unavoidable in case of an automatic approach to differentiate 'real' building changes from false alarms. However, if the quality of the input DSMs is low, thresholds for the filters have to be set high to filter out most of the model errors. Consequently, also small 'real' building changes will be rejected from the change model. In the presented case study, this will happen when the height difference of the changed building is smaller than $2.5 \mathrm{~m}$ and the area difference is smaller than $25 \mathrm{~m}^{2}$. Both models, generated in the context of this research, are of high quality and allowed to set the thresholds relatively low. Small buildings can still be detected, without a large presence of false alarms in the 3D change model. The robustness of the 3D change detection approach is illustrated with the example of the detected fairground attractions on Saint Peter's square. We also expected to detect small structural changes in backyards, such as newly constructed (illegal) barns and garden houses. However, due to the coverage of mostly large trees, this was not the case.

At present, dense lidar data sets are scarce and mostly they consist of small coverage. Systematic acquisitions with regional or global coverage, as existing for aerial and satellite image data sets, are not available for lidar. However, with technological advances, we can expect an increase of lidar acquisitions with higher coverage in the (near) future. 


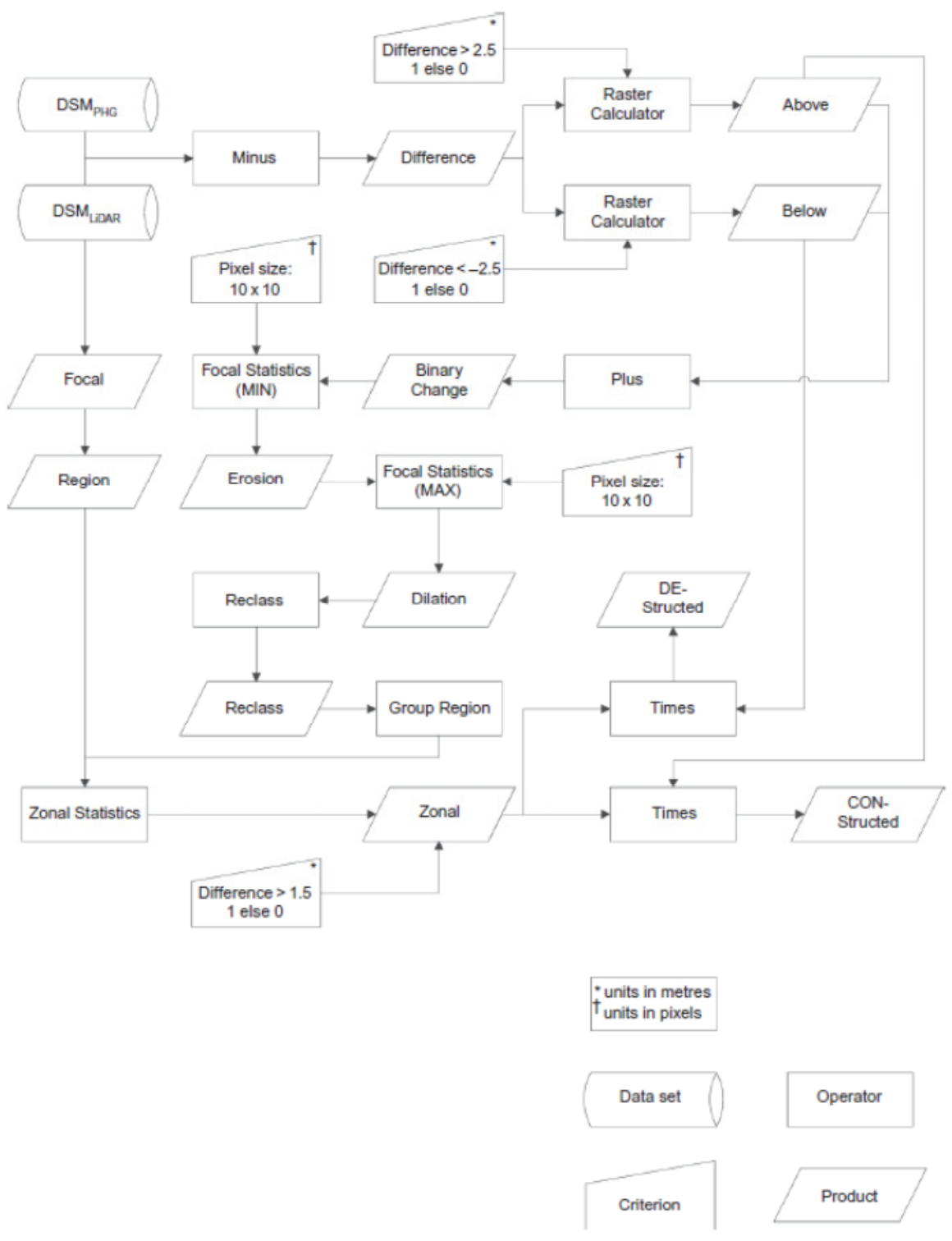

Figure 11. 3D change detection workflow.

Most likely, this will elevate 3D change detection studies of urban areas to the forefront of research.

\section{ACKNOWLEDGEMENTS}

The Belgian Science Policy Office (BELSPO) and the Research Foundation Flanders (FWO) are gratefully acknowledged for funding the work presented in this article. The authors would like to express their gratitude to the Flemish Geographical Information Agency (AGIV) for providing the aerial image data and the municipality of Ghent for the lidar data. 


\section{REFERENCES}

Adams, R., and L. Bischof. 1994. "Seeded Region Growing." Pattern Analysis and Machine Intelligence 16: 641-7.

Alharthy, A., and J. Bethel. 2002. "Heuristic Filtering and 3D Feature Extraction from LiDAR Data." International Archives of Photogrammetry and Remote Sensing 34: 29-34.

Asal, F., M. Smith, and G. Priestnall. 2000. "Combining LIDAR and Photogrammetry for Urban and Rural Landscape Studies." International Archives of Photogrammetry and Remote Sensing 33: 4450 .

Axelsson, P. 1999. "Processing of Laser Scanner Data: Algorithms and Applications." ISPRS Journal of Photogrammetry and Remote Sensing 54: 138-47.

Baltsavias, E. 1991. "Multiphoto Geometrically Constrained Matching." PhD thesis, Institute of Geodesy and Photogrammetry, Zürich, Switzerland.

Baltsavias, E. 1999. "A Comparison between Photogrammetry and Laser Scanning." ISPRS Journal of Photogrammetry and Remote Sensing 54: 83-94.

Baltsavias, E., and A. Gruen. 2003. "Resolution Convergence: A Comparison of Aerial Photos, LiDAR and Ikonos for Monitoring Cities." In Remotely-Sensed Cities, edited by V. Mesev, 47-82. London: Taylor \& Francis.

Berthod, M., L. Gabet, G. Giraudon, and J. L. Lotti. 1995. "High-Resolution Stereo for the Detection of Buildings." In Automatic Extraction of Man-Made Objects from Aerial and Space Images, edited by A. Gruen, P. Kuebler, and P. Agouris, 135-44. Basel: Birkhäuser Verlag.

Blaschke, T. 2010. "Object Based Image Analysis for Remote Sensing." ISPRS Journal of Photogrammetry and Remote Sensing 65: 2-16.

Böhler, W., V. Bordas, and A. Marbs. 2003. "Investigating Laser Scanner Accuracy." International Archives of Photogrammetry and Remote Sensing 34: 696-701.

Bretar, F., M. Chesnier, and M. Pierrot-Deseilligny. 2004. "Terrain Modeling and Airborne Laser Data Classification Using Multiple Pass Filtering." International Archives of Photogrammetry and Remote Sensing 35: 314-19.

Breunig, M., and S. Zlatanova. 2011. "3D Geo-Database Research: Retrospective and Future Directions." Computers \& Geosciences 37: 791-803.

Briese, C., N. Pfeifer, and P. Dorninger. 2002. "Applications of the Robust Interpolation for DTM Determination." International Archives of Photogrammetry and Remote Sensing 34: 55-61. Chaabouni-Chouayakh, H., T. Krauss, P. D'angelo, and P. Reinartz. 2010. "3D Change Detection Inside Urban Areas Using Different Digital Surface Models." International Archives of Photogrammetry, Remote Sensing and Spatial Information Sciences 38: 86-91.

Chaplot, V., F. Darboux, H. Bourennane, S. Leguédois, N. Silvera, and K. Phachomphon. 2006. "Accuracy of Interpolation Techniques for the Derivation of Digital Elevation Models in Relation to Landform Types and Data Density." Geomorphology 77: 126-44.

Coluzzi, R., N. Masini, and R. Lasaponara. 2011. "Flights Into the Past: Full-Waveform Airborne Laser Scanning Data for Archaeological Investigation." Journal of Archaeological Science 37: 2061-70.

Cui, Y., and S. Ge. 2003. "Autonomous Vehicle Positioning with GPS in Urban Canyon Environments." IEEE Transactions on Robotics and Automation 19: 15-25.

Douglas, D., and T. Peucker. 1973. "Algorithms for the Reduction of the Number of Points Required for Represent a Digitized Line or Its Caricature." Canadian Cartographer 10: 112-22. 
Elberink, S., and H. Maas. 2000. "The Use of Anisotropic Height Texture Measures for the Segmentation of Airborne Laser Scanner Data." International Archives of Photogrammetry and Remote Sensing 33: 678-84.

Förstner, W. 1999. "3D-City Models: Automatic and Semi-Automatic Acquisition Methods." In Photogrammetric Week '99, edited by D. Fritsch and R. Spiller, 291-303. Heidelberg: Wichman Verlag.

Gabet, L., G. Giraudon, and L. Renouard. 1997. "Automatic Generation of High Resolution Urban Zone Digital Elevation Models." ISPRS Journal of Photogrammetry and Remote Sensing 52: 3347.

Gehrke, S., K. Morin, M. Downey, N. Boehrer, and T. Fuchs. 2010. "Semi-Global Matching: An Alternative to LiDAR for DSM Generation?" International Archives of Photogrammetry, Remote Sensing and the Spatial information Sciences, 38: 6 p. (on CD-ROM).

Gruen, A. 1985. "Adaptive Least Squares Correlation: A Powerful Image Matching Technique." South Africa Journal of Photogrammetry, Remote Sensing and Cartography 14: 175-87.

Haala, N., and M. Kada. 2010. "An Update on Automatic 3D Building Reconstruction." ISPRS Journal of Photogrammetry and Remote Sensing 65: 570-80.

Jacobsen, K. 2006. "Digital Surface Models of City Areas by Very High Resolution Space Imagery." In EARSeL Workshop of the SIG Urban Remote Sensing, Berlin, Germany, March 2-3, 2006, $10 p$ (on CD-ROM).

Jung, F. 2004. "Detecting Building Changes from Multitemporal Aerial Stereopairs." ISPRS Journal of Photogrammetry and Remote Sensing 58: 187-201.

Kanade, T., and M. Okutomi. 1994. "A Stereo Matching Algorithm with an Adaptive Window: Theory and Experiment." Pattern Analysis and Machine Intelligence 16: 920-32.

Kolbe, T. H., G. Gröger, and L. Plümer. 2005. "CityGML: Interoperable Access to 3D City Models." In First International Symposium in Geo-Information for Disaster Management, edited by Van Oostrom, S. Zlatanova, and E. M. Fendel, Delft, the Netherlands, March 21-23, 2005, 883-99. Heidelberg: Springer.

Kraus, K., W. Karel, C. Briese, and G. Mandlburger. 2006. "Local Accuracy Measures for Digital Terrain Models." The Photogrammetric Record 21: 342-54.

Krzystek, P. 2003. "Filtering of Laser Scanning Data in Forest Areas Using Finite Elements." International Archives of Photogrammetry and Remote Sensing, 34: 6 p. (on CD-ROM).

Kutner, M., C. Nachtsheim, J. Neter, and W. Li. 2005. Applied Linear Statistical Model. 1396 p. New York: McGray-Hill.

Lu, D., P. Mausel, E. Brondizio, and E. Moran. 2004. "Change Detection Techniques." International Journal of Remote Sensing 25: 2365-401.

Prathumchai, K., and L. Samarakoon. 2006. "Elevation Surface Interpolation of Point Data Using Different Techniques: A GIS Approach." In 27th Asian Conference on Remote Sensing, Ulaanbataar, Mongolia, October 9-13, 2006, 8 p. (on CD-ROM).

Radke, R. J., S. Andra, O. Al-Kofahi, and B. Roysam. 2005. "Image Change Detection Algorithms: A Systematic Survey." IEEE Transactions on Image Processing 14: 294-307.

Rigo, G., and E. Parlow. 2007. "Modelling the Ground Heat Flux of an Urban Area using Remote Sensing Data." Theoretical and Applied Climatology 90: 185-99.

Rottensteiner, F., J. Trinder, S. Clode, and K. Kubik. 2007. "Building Detection by Fusion of Airborne Laser Scanner Data and Multi-Spectral Images: Performance Evaluation and Sensitivity Analysis." ISPRS Journal for Photogrammetry and Remote Sensing 62: 135-49. 
Shepard, D. 1968. "A Two-Dimensional Interpolation Function for Irregular Spaced Data." In 23rd ACM National Conference, 1968, New York, 517-24.

Sithole, G., and G. Vosselman. 2005. "Filtering of Airborne Laser Scanner Data Based on Segmented Point Clouds." International Archives of Photogrammetry and Remote Sensing 36: 6671.

Soille, P. 2003. Morphological Image Analysis: Principles and Applications, 391 p. New York: Springer-Verlag.

Stad Gent. 2004. Algemeen Bouwreglement: Stedenbouwkundige Verordening Van De Stad Gent (Construction Permit Regulations). Belgium: Stad Gent.

Stal, C., J. Bourgeois, P. De Maeyer, G. De Mulder, A. De Wulf, R. Goossens, T. Nuttens, and B. Stichelbaut. 2010. "Kemmelberg (Belgium) Case Study: Comparison of DTM Analysis Methods for the Detection of Relicts from the First World War." In EARSeL Symposium "Remote Sensing for Science, Education and Culture", edited by R. Reuter, Paris, France, May 31-June 4, 65-72.

Tack, F., G. Buyuksalih, and R. Goossens. in press. "Assessment of a Photogrammetric Approach for Urban DSM Extraction from Tri-Stereoscopic Satellite Imagery." The Photogrammetric Record. Vosselman, G. 2000. "Slope Based Filtering of Laser Altimetry Data." International Archives of Photogrammetry and Remote Sensing 33: 935-42.

Vosselman, G., and H. Maas. 2001. "Adjustment and Filtering of Raw Laser Altimetry Data." In OEEPE Workshop on Airborne Laserscanning and Interferometric SAR for Detailed Digital Elevation Models, Stockholm, Sweden, March 1-3, 2001, 11 p. (on CD-ROM).

Wallis, R. 1976. "An Approach to the Space Variant Restoration and Enhancement of Images." In Symposium on Current Mathematical Problems in Image Science, 1976, Monterey, CA, 641-62. Weidner, U., and W. Förstner. 1995. "Towards Automatic Building Extraction from High-Resolution Digital Elevation Models." ISPRS Journal of Photogrammetry and Remote Sensing 50: 38-49.

Zhang, K., S. Chen, D. Whitman, M. Shyu, J. Yan, and C. Zhang. 2003. "A Progressive Morphological Filter for Removing Non-Ground Measurements from Airborne LIDAR Data." IEEE Transactions on Geoscience and Remote Sensing 41: 872-82.

Zhang, L., and A. Gruen. 2006. "Multi-Image Matching for DSM Generation from Ikonos Imagery." ISPRS Journal of Photogrammetry and Remote Sensing 60: 195-211. 